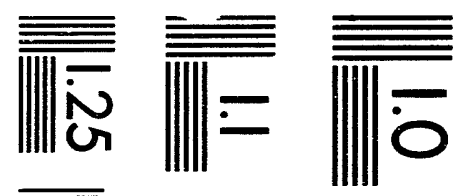

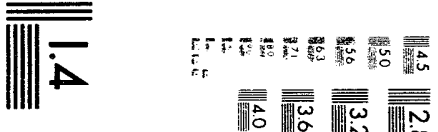

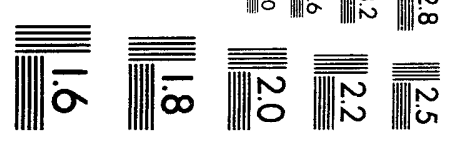



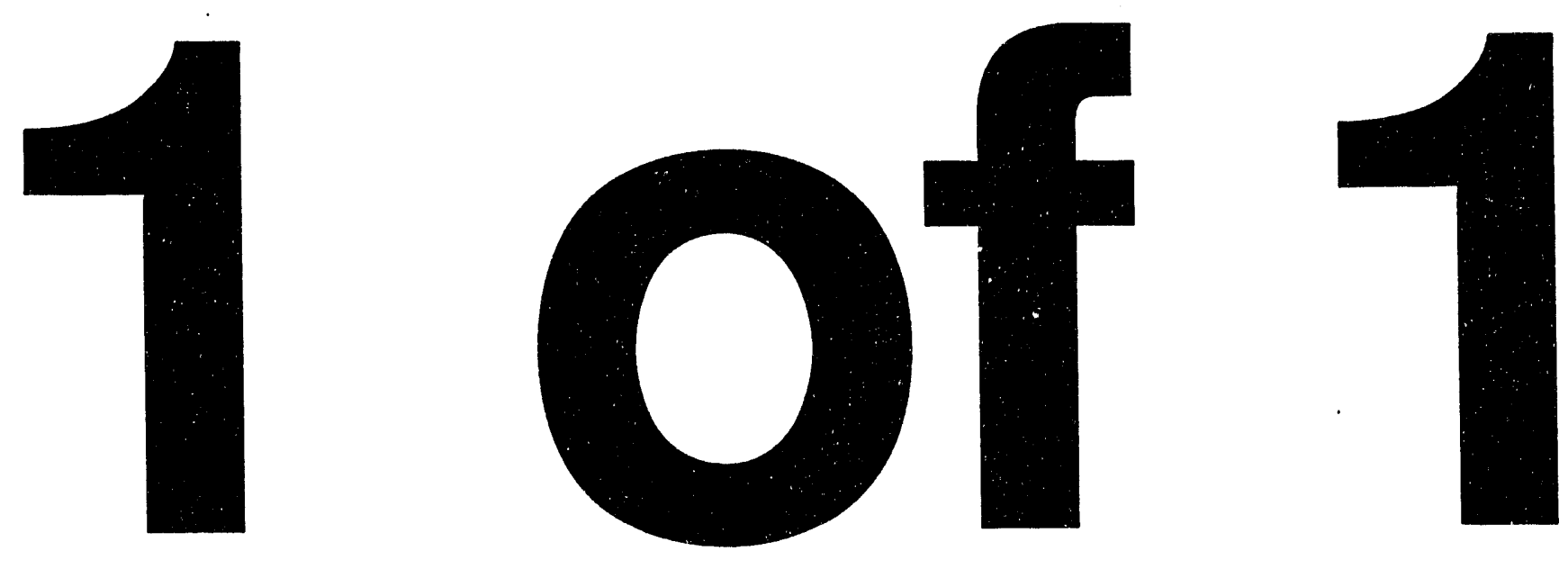


\title{
Development of Accelerator Radiation Protection at the SSC
}

\author{
T. Toohig \\ Superconducting Super Collider Laboratory* \\ 2550 Beckleymeade Ave. \\ Dallas, TX 75237
}

November 1993

\footnotetext{
"Operated by the Universities Research Association, Inc., for the U.S. Department of Energy under Contract
} No. DE-AC35-89ER40486. 


\title{
Development of Accelerator Radiation Protection at the SSC
}

\author{
T. Toohig
}

\begin{abstract}
The design of the Superconducting Super Collider evolved over a series of studies from 1984 to 1989. Considerations of concentration of radiation sources and provisions for operational control and monitoring of radiation were determining elements in the design concepts for the facility. The development of the designs involved an extension of the range of applicability of energy deposition and radiation shielding codes beyond the $3 \mathrm{TeV}$ level of the proposed UNK collider to $20 \mathrm{TeV}$ for single beam effects and to $40 \mathrm{TeV}$ in the collision regions. This extrapolation was complicated by the newly discovered, very energetic muons from short-lived states associated with heavy quark states. The design guideline for radiation protection was specified to be $10 \mathrm{mRem} / \mathrm{yr}, 10 \%$ of the Federal limit. In order to limit the amount of land required for the facility, which would extend over some $250 \mathrm{mi}$. sq., the configuration of the land to be acquired was tailored to the requirements for radiation containment below the levels of the guideline.
\end{abstract}




\subsection{CONCEPT INITIATION - THE DESERTRON}

In a summary paper on Fermilab and the Future of HEP written in the summer of 1982 at the Snowmass Summer Study sponsored by the Division of Particles and Fields (DPF) of the American Physical Society (APS), Leon Lederman, then the Director of Fermilab, discussed concepts for a new accelerator laboratory to provide up to 40 $\mathrm{TeV}$ of energy in the center of mass, ${ }^{1}$ to be compared with $2 \mathrm{TeV}$ at the Fe milab Tevatron. The choice of the energy scale was based on theoretical reasoning relating to the physics of the electroweak sector, that had been presented by $S$. (ilashow at a Rome workshop in the previous October. Examining accessible technology to achieve this goal and extrapolating from the Fermilab construction techniques, Lederman eoncluded that such a machine would have to be built in the desert for sufficient uninhabited land to be found to contain the facility. ()n this hasis I ederman dubbed the concept the "Multi-TeV-in-the-Desert scheme." The title was later elided to "I)esertron."

\subsection{CORNELL WORKSHOP - EXPLORING THE PARAMETERS}

As an outgrowth of the discussions at the 1982 DPF Summer Study, a workshop was held at Cornell University during the following Spring, March 28-April 2, 1983, to consider further the technical issues pertaining to a $20 \mathrm{TeV} \times 20 \mathrm{TeV}$, proton-proton collider facility. ${ }^{2}$ The convening of this workshop was encouraged by the administrators of the US laboratories engaged in particle physics, as well as by relevant entities of the Federal (iovernment and many scientists in the field. The workshop was divided into four task groups, of which the Systems tingineering task group, with Prof. 13. 1). McDaniel of Cornell as secretary, was charged with considering the aspects of civil construction and shielding, along with other related topics.

The basic considerations that have guided all subsequent design efforts for environmental radiation shielding were developed by this task force, vid. the hadron shielding required immediately downstream of a full-beam loss point, and the penetration of muons far downstream $(>1.7 \mathrm{~km})$ from such a loss point. Under the assumption that the accelerator would be housed in a tunnel close to the surface, similar to the Fermilab tunnel, the emphasis in the considerations for radiation shielding at Cornell was on protection of the general public at a surface location above the tunnel.

Hadron and muon shielding calculations for the absorption of $20 \mathrm{TeV}$ protons were generated for the workshop by $\mathrm{A}$. van (iinneken of Fermilab using an extrapolation from lower energies of the CASIM code. Hadron shielding curves were also generated by R. H. Thomas and J. B. McCaslin of L.BL using a Moyer Model extrapolation. Hadron and muon shielding calculations were also generated independently by R. Slansky of I.ANI by invoking theoretical considerations to scale from existing, lower energy data. All of these calculations were in reasonable agreement among themselves, which gave some confidence in their validity. These were then used to estimate the shielding required to reduce the surface dose resulting from a loss of 1()$^{14}$ protons to $\leq 1(0) \mathrm{mRem}$, the specified guideline for dose from an accidental loss. From these calculations the workshop concluded that, for an assumed shielding density of $1.8 \mathrm{gm} / \mathrm{cm}^{3}$, a transverse shield thickness of 6 meters, and a longitudinal shield length of $>1.7 \mathrm{~km}$ would be required to shield for the loss of a 20) TeV beam of 10$)^{14}$ protons.

\subsection{PRE-CONCEPTUAL REPORTS - EXPLORING THE SCOPE}

Subsequent to the Cornell Workshop, R. Slansky of the Ios Alamos National Laboratory (LANL) compiled a Site Atlas for the Superconducting Super Collider which consisted of unsolicited contributions from groups of physicists in 6 states tentatively identifying possible sites in their states for an SSC ring. ${ }^{3}$ Based on the deliberations from the Cornell Workshop, a site would have to accommodate accelerator rings

with diameters ranging from 15 to 3 () miles, corresponding to magnet field levels of 6 to 3 Tesla. It was notable in the atlas that, with the exception of an extension of the Fermilab site in Illinois, all of the proffered sites 
were in the Southwest, reflecting the "Desertron" concept. The Atlas served to crystallize various requirements for siting the SSC, like the flatness criterion for muon protection which is noted below.

The sites proffered for the Atlas emphasized terrain-following, distorting the orbit of the accelerator to follow the local ground contours. This feature was motivated by the perception that excavation costs for the tunnel could be minimized hy limiting to the depth required for radiation shielding the trenching to emplace the ring. The range of muons from interactions in the experimental areas and from the potential accidental loss of the circulating beam imposed limits on the acceptable vertical bend angles for terrain following to avoid having the muons breach the surface. This, in turn, imposed limits on the variation of surface contours for near-surface sites.

At the time of the Reference Designs Study in 1984, Slansky prepared a Second Edition of the Site Allas ${ }^{4}$ as a resource for exploring siting aspects of the Study. A notable change from the first edition was the inclusion of two deep tunnel configurations. These two submissions were based on the Fermilab Tevatron as injector and drew on the extensive tunneling experience from the Tunnel and Reservoir Project (TARP) in the Chicago area. Inclusion of the deep lunnel sites revealed the advantages of this approach in minimizing environmental and surface radiation concerns. However, it also highlighted concerns about radioactive contamination of ground water supplies.

\subsection{REFERENCE DESIGNS STUDY (RDS) - SETTING THE PARAMETERS}

In December, 1983, the Directors of the U. S. high energy physics laboratories chartered the National SSC RDS to review in detail the technical and economic feasibility of various options for creating a $20 \mathrm{TeV} \times$ 20) TeV, proton-proton colliding beams facility. ${ }^{5}$ The Reference Designs Study report was not intended to be either a design proposal or a site preference study, but to extend previous technical and economic feasibility studies for such a facility. For the RISS a radiation exposure guideline of $10 \mathrm{mrem} / \mathrm{yr}$ was adopted for the design of facilities and shielding in areas accessible to the general public. This guideline was $10 \%$ of the Federal limit for exposure used in the Cornell Workshop. The guideline was affirmed as prudent and feasible by the DOE Review Committee for the RDS."

Three different magnet types were examined in this study a superconducting, 6 Tesla, 2-in-1, cold-iron magnet developed at Brookhaven National Laboratory (' 'L), a superconducting, 5 Tesla, warm-iron magnet derived from the Tevatron at Fermilab, and a superlerric, 3 Tesla, magnet championed by the Texas Accelerator Center. From an environmental radiation viewpoint the principal differentiating characteristic among the three designs was the circumference of the rings, $56 \mathrm{mi}$. (Design A, 6.5 Tesla), 70.4 mi. (Design B, 5 Tesla) and $108 \mathrm{mi}$. (Design C, 3 Tesla). Since the cone of muons from an accidental loss of beam is approximately tangent to the ring at the loss point, the width of the radiation zone outside the ring which must be controlled would be an inverse function of the curvature of the ring, and, therefore, would be a function of the magnet field strength.

In order to focus and facilitate environmental and civil construction considerations, and to provide a vehicle for a reliable cost estimate, a Median Site was defined from the site descriptions provided in the Site Atlas. Quadrants were extracted from site descriptions in the Atlas and stitched together to form a single site which contained the range of variability of the suggested sites. The provenance of the Median Site ensured that it would lie within the range of acceptability for a real site. Because of the bias in the Atlas towards near-surface sites; the costs and schedules derived for the Median Site would reflect a cut-and-cover approach to the construction. The depth of cover required for radiation shielding is a major concern for such a site.

A noteworthy feature of the Reference Designs Study is the dispersion of major facilities, and, therefore, of significant radiation sources, around the periphery of the nearly-circular ring. Experimental areas are located at $2,4,8$, and $100^{\prime}$ 'clock, the injection straight section is located at $90^{\prime}{ }^{\prime} \mathrm{clock}$, the beam abort at $10^{\prime}$ 'clock, and future experimental halls at 6 and $120^{\circ}$ clock. This widespread dispersion strongly impacts considerations of 
radiation protection, monitoring of environmental radiation, radiation protection, and land acquisition related to containment of radiation.

To facilitate the RI)S and the Fermilab study described helow, A. Van(iinneken at Fermilab extended to $\sqrt{s}=4() \mathrm{TeV}$ the model for p-nucleus interactions in the CASIM code by extrapolating data from the Fermilab Tevatron, from the CFRN ISR and from the CERN pbar-p collider. A significant feature of this extrapolation was the incorporation of very energetic muons from the newly-discovered quark states. The code was used to generate shiclding curves for the RDS and was subsequently used to develop a handbook of radiation shielding curves for proton bc an loss at $20 \mathrm{TeV}$ and p-pcollisions at $\sqrt{s}=40$ TeV. ${ }^{7}$ The code was also used to estimate the energy deposition in the magnets of the SSC with particular emphasis on beam loss in the interaction regions.

Following publication of the RDS and its review by the D()E, the report with its review comments was used as a basis ${ }^{8}$ for preparing for D)( )E a Siting Parameters Document." This document was developed as the technical core for an invitation for site proposals from interested parties. It consisted of a technical advisory on SSC site criteria and a catalog of information to be solicited from proposers for evaluating the suitability of proffered sites. Based on the design assumptions in the RI)S, the hadron shield for the Collider ring in the advisory was specified as a 2()-foot annulus around the tunnel. In order to contain the muon radiation from an aceidental loss, which was assumed to be tangential to the ring, a width of $7(0)$ feet radially out ward from the center of the ring was specified for a 6 Tesla ring, and 3.50 feet for a 3 Tesla ring, the two field values still under consideration. The combination of the hadron and muon shielding criteria resulted in a specification, for the Collider housed in a 9 it. diameter tunnel, of a radiation zone 25 feet, above and betow the plane of the accelerator, $7(K)$ feet wide outside the ring, and 25 leet inside the ring.

For the high field case, an additional radiation consideration is the presence of significant synchrotron radiation, for the first time in a proton accelerator, from the bending of the $20 \mathrm{TeV}$ protons in the magnetic field. In the high-field case this radiation can be responsible for half of the heat load on the superconducting system at 4.5 Kelvin.

\subsection{THE FERMILAB SSC DESIGN - A FOCUSED CONCEPT}

During late 1983 a task force was formed at Fermilab under the leadership of Dr. Helen Fdwards to develop a design for an SSC hased on the Fermilab Tevatron as injector. ${ }^{10}$ The task force, drawn from within the Laboratory, was supplemented by geotechnical expertise from Harza Fingineering Co.," a major Chicago engineering firm with considerable underground experience on the TARP project, and geological help from the Illinois Bureau of (ieology. Since Fermilab was an operating accelerator laboratory with recent construction experience in superconducting accelerator technology, considerable knowledge and experience were a vailable to the task force in all relevant disciplines. These disciplines included cryogenic operation and safety, monitoring and control of environmental radiation, and radiation damage and radioactivation of accelerator systems. In March 1984 a rather complete draft report was published by the task force, which included a detailed geotechnical study for construction of the tunnel in the dolomite underlying the region.

The Fermilab study, involving as it did experienced accelerator, radiation, construction, and operations personnel, explored and defined most of the questions relevant to the design, construction and operation of the SSC, and became a primary resource for subsequent studies and designs. In particular, this study developed the concept and demonstrated the feasibility of clustering the injection and interaction regions, thus localizing the principal environmental radiation sources. Iocalization of these facilities reduces the required staffing for the $L$ aboratory and lessens the requirements for land acquisition.

In developing a detailed design for the Collider on a specific site it was necessary for the Fermilab task force to confront and mitigate the activation of ground water present in the host rock, to develop a design for access shafts and underground facilities which would preclude radiation leakage to the surface, and to explore 
in a concrete geographical setting the feasibility of operating a series of isolated facilities located many miles from the operations center without compromising requirements for monitoring, control and mitigation of adverse environmental impacts.

\subsection{CONCEPTUAL DESIGN REPORT (CDR) - FIXING THE PARAMETERS}

In March, 1984 the IOH assigned to the Universities Research Association (URA) responsibility for oversight of the national SSC effort during the R\&D) and preconstruction phases. The URA is the consortium of universities that built and now operates Fermilab. By the fall of 1984. URA had formed the SSC Central Design (iroup (CD) (i) to carry out its responsibilities of directing and coordinating the national R\&D work. The principal activities of the $\mathrm{CD}$ ( $\mathrm{f}$ for $\mathrm{FY} 198.5$ were 10 conduct a diversified $\mathrm{R} \& \mathrm{D}$ ) effort on model magnets and cryostats to provide the technical basis for selection of one of tive superconducting magnet designs as the basis for the SSC, and to initiate a conceptual design of the facility based on that selection. The results of this conceptual design effort were published as a Conceptual Design Report 12 in March 1986 and reviewed by the D()F:12 in May 1986. As noted in the discussion of the RIDS, above, the choice of a magnet and the configuration of facilities determine certain radiation parameters which impact siting requirements. The Conceptual Design, thus, provided the technical basis for an updated siting parameters document to be used in the site selection process.

Since the major concerns relative to radiation during the Conceptual Design phase related to environmental effects and shielding of the general public, responsibility for radiation calculations and the design of shielding lay primarily with the Conventional Facilities Division. There was no full time radiation physicist included in the small (C)(i staff, so the Division relied heavily on the expertise of the radiation physics community. A series of workshops was convened by the Deputy Head of the Conventional Facilities Division to explore the radiation parameters for the facility. These included a workshop on environmental radiation, ${ }^{14}$ and one on the radiological aspects of SSC operations. ${ }^{15}$ A principal goal of the former workshop was the cross-calibration of CASIM, FI,UKA, and HETC with one another and with experimental data. The latter focussed on energy deposition in components and primary beam absorbers. (ienerous contributions of time and expertise were made by Stevenson and others at CFRN, by Coulson, Cossairt and their colleagues at Fermilab, hy Mokhov and his group at Protvino, and by Thomas and the LBI, group.

To proceed from principles and calculational models to the design of tunnels, heam dumps and other facilities a defined set of design parameters, or ranges of design parameters, such as beam energy, intensity, luminosity, annual operations, etc., is necessary. Towards this end a Parameters Committee was appointed by the Director of the CDC (o establish a Parameters List to be used as a basis of design for the shielding, beam dumps, and land requirements for the facility. Relevant parameters are discussed below.

\subsection{SSC Radiation Criteria: Operations Parameters}

In general, the design of the accelerator facility must consider instantaneous, annual and cumulative radiation doses. Annual and cumulative doses can be controlled administratively. However, the design of the facility must preclude instantaneous doses in accessible locations that are above defined legal limits. Annual doses are dependent upon the annual operating cycle of the facility. For this reason, and especially for environmental considerations, the design of the facility must include a set of assumptions about the operating cycle for which the design is valid. Those assumptions on which the Siting Parameters document is based are listed in Table 1. 
Table 1. Annual operating cycle.

\begin{tabular}{|l|c|}
\hline \multicolumn{1}{|c|}{ Parameter } & Value \\
\hline Operations for Physics - scheduled & $5,000 \mathrm{hrs} / \mathrm{yr}$ \\
\hline Accelerator Studies - scheduled & $1,000 \mathrm{hrs} / \mathrm{yr}$ \\
\hline Availability & $80 \%(=4800 \mathrm{hrs} / \mathrm{yr})$ \\
\hline Collider Beam Fills - full energy \& intensity & $500 / \mathrm{year}$ \\
\hline Collider Beam Fills - injection energy, full intensity & $1,000 / \mathrm{ring} / \mathrm{yr}$ \\
\hline HEB Fills - Collider injection (14 cycles/Collider ring) & $28,000 / \mathrm{yr}$ \\
\hline HEB Fills - Test beams (1012 protons/fill, 3 min/cycle, $6,000 \mathrm{hr} / \mathrm{yr})$ & $120,000 / \mathrm{yr}$ \\
\hline
\end{tabular}

\subsection{SSC Radiation-Related Defining Parameters}

The design parameters for the Conceptual Design which determine the radiation characteristics of the facility are listed in Table 2, where bracketed figures are for future upgrades.

Table 2. Radiation-defining parameters.

\begin{tabular}{|l|c|}
\hline \multicolumn{1}{|c|}{ Parameter } & Value \\
\hline Energy & $20 \mathrm{TeV} / \mathrm{beam}$ \\
\hline Luminosity & $10^{33}\left(10^{34}\right) \mathrm{cm}^{-2} \mathrm{sec}^{-1}$ \\
\hline Peak Magnet Field, Arc Dipoles & $6.6 \mathrm{Tesla}$ \\
\hline Number of Interaction Points & $4(6)$ \\
\hline Distribution of IP's & Clustered \\
\hline
\end{tabular}

\subsection{SSC Radiation-Related Derived Parameters}

The defining parameters for the facility lead to a set of derived quantities which fix the radiation levels to be shielded, and the extent of related radiation fields. These derived parameters are listed in Table 3, along with their impacts on the design of the facility. 
Table 3. Radiation-related derived parameters.

\begin{tabular}{|c|c|c|}
\hline Parameter & Value & Impacted \\
\hline \multicolumn{3}{|l|}{ Collider } \\
\hline Beam Intensity & $1.3 \times 10^{14} /$ beam & Accidental loss levels \\
\hline Bending Radius of Dipoles & 12.2 kilometers & Width of nuon zone in arcs \\
\hline Interaction Rate & $10^{8 / \mathrm{sec}}$ & Dose levels at interaction regions \\
\hline Stored Eriergy & $418 \mathrm{MJ} /$ beam & Beam absorber \\
\hline \multicolumn{3}{|l|}{ Injector } \\
\hline Energies- Linac/LEB /MEB/HEB & $\begin{array}{l}600 \mathrm{MeV} / 8 \mathrm{GeV} / \\
100 \mathrm{GeV} / 1 \mathrm{TeV}\end{array}$ & Muon shielding \\
\hline $\begin{array}{l}\text { Intensities - Linac/LEB /MEB/ } \\
\text { HEB }\end{array}$ & $\begin{array}{l}5 \times 10^{12} \mathrm{sec}^{-1} / \\
5 \times 10^{12} \mathrm{sec}^{-1} / \\
9 \times 10^{11} \mathrm{sec}^{-1} / \\
1.8 \times 10^{11} \mathrm{sec}^{-1}\end{array}$ & $\begin{array}{l}\text { Residual activation, ground water } \\
\text { protection }\end{array}$ \\
\hline
\end{tabular}

\subsection{SSC Radiation-Related Design Choices}

Two models for the overall layout of the facility were available to the $\mathrm{CD}$ ( $i$, the Fermilab model of clustering the straight sections of the Collider lattice, and the the distributed arrangement of the RIS. CDG analyzed the economic, environmental and operational characteristics of these arrangements relative to one another, and adopted for the Conceptual Design a lattice consisting of two arcs of nearly $180^{\circ}$ each joined by a cluster containing four straight sections on either side of the ring. In this design two adjacent straight sections, one for clockwise the other for counterclockwise, serve for injection of the beams from the HEB into the Collider and extraction of the Collider beams into the beam dumps. This arrangement concentrates the normal beam loss points into the two clusters, greally simplifying the control and monitoring of environmental and residual radiation levels. Up to four additional interaction points could be accommodated in each cluster by incorporation of an alternate beam bypass around the initial set of collision points.

The injection energy into the Collider in the CDR, $1 \mathrm{TeV}$, preserved the option of using the Tevatron at Fermilab as the Injector for the SSC. This energy level was believed to be adequate for Collider injection, but not optimal, especially in view of the $4 \mathrm{~cm}$ aperture of the Collider dipoles.

The Test Beams in the CDR were based upon an analysis of requirements compiled by a Test Beams Working Group at Snowmass 84. That analysis concluded that a beam energy of $1 \mathrm{TeV}$ and an intensity of $\left\langle 1()^{7} \mathrm{~Hz}\right.$. would be adequate for all of the foreseen needs for testing detector components. The activation of target stations, and the environmental impacts from test beams at this level would be negligible compared with the Collider ring and far less than from the fixed target program at Fermilab. This low demand for intensity results in modest beam lines with modest target stations. Since a very long beam spill is possible from a superconducting machine, the design adopted used switching magnets, rather than splitters, to feed two target stations sequentially on the same spill. Four secondary beams are derived from the two target stations to provide four experimental stations, one for each of the experiments. Because of the long spill, the duty factor for each of the stations is still very good even though they share the spill. Since the intensity for the test beams was low, the intensity requirements for all of the Injector accelerators were determined by the Collider fill. 


\subsection{SSC Radiation Criteria: Design Assumptions}

For purposes of calculating the environmental innact of the siting and operation of the facility, conservative criteria were adopted in the Conceptual Design for the intensity of radiation sources and for the permissible levels of radiation dose. In particular, the luminosity was assumed to be $1\left(0^{34} \mathrm{~cm}^{-2} \mathrm{sec}^{-1}\right.$, a factor of 10 above the project specification, and the guideline for maximum exposure for the general public was assumed to be $10 \mathrm{mrem} / \mathrm{yr}$, a factor of 1 () below the legal limit for routine operation of a radiation-generating device. The ensemble of radiation criteria used for the basis of design is given in Table 4.

Table 4. Radiation criteria, design assumptions.

\begin{tabular}{|l|l|}
\hline \multicolumn{1}{|c|}{ Parameter } & \multicolumn{1}{c|}{ Design Assumption } \\
\hline Collider Beam Intensity, Accidental Loss & $4 \times 10^{14}$ protons/beam \\
\hline Collider Luminosity & $10^{34} \mathrm{~cm}^{-2} \mathrm{sec}^{-1}$ \\
\hline Collider Accidental Loss Frequency & $1 / \mathrm{yr}$ somewhere in the ring \\
\hline HEB Accidental Loss Frequency & $1 / \mathrm{yr} \mathrm{somewhere} \mathrm{in} \mathrm{the} \mathrm{ring}$ \\
\hline Design Maximum Dose Limit, OHf-site & $10 \mathrm{mrem} / \mathrm{yr}$ \\
\hline Design Maximum Exposure, General Public & $10 \mathrm{mrem} / \mathrm{yr}$ \\
\hline Soil Density, Collider Ring and IR's & $1.8 \mathrm{gm} / \mathrm{cm}^{3}$ \\
\hline Soil Density, Beam Absorber Regions & $2.24 \mathrm{gm} / \mathrm{cm}^{3}$ \\
\hline
\end{tabular}

\subsection{SITING THE FACILITY - PRACTICAL CONSIDERATIONS}

\subsection{Invitation for Site Proposals (ISP) - Radiation Containment Provisions}

Following the DOE review of the Conceptual Design Report a major effort of the URA CDG was to refine the siting parameters with a view (0) issuance by D()E of an ISP. To this end a new Siting Parameters Document was prepared by the CID( ${ }^{16}$ Making use of the improved radiation calculations of VanGinneken, and allowing for a luminosity of a factor of 10 higher than was adopted for the earlier, 1985, Siting Parameters Document, $10^{34} \mathrm{~cm}^{2} \mathrm{sec}{ }^{1} \mathrm{vs} .1()^{33} \mathrm{~cm}{ }^{2} \mathrm{sec}{ }^{1}$, a primary radiation shicld was specified of 3() $\mathrm{ft}$. around a 10 -ft. diameter tunnel, using the soil densities assumed under radiation criteria, above. Using VanGinneken's curve, independently verified hy Mokhov, the minimum width of the muon zone radially outside the ring was defined to be $750 \mathrm{ft}$. Making use of modifications to the MARS code based on early work by Keefe \& Noble to include trapping of muons in the accelerator lattice, a 15()-ft. wide muon zone was defined radially inward from the center of the ring. This document was a primary basis for the ISP for the SSC issued by DOE in April 1987.17

Since lattice refinements were still being actively pursued at the time of the issuance of the ISP, some latitude was required in the acquisition of land. The lattice designers tested the impact on the location of the ring of the full width of the range of lattices being studied, and found that the variation of positions of the magnet elements in the arcs was quite small, given a fixed design field of 6.6T for the superconducting dipoles. To accommodate this variability, a l()()-ft. wide band of land was specified for the arcs within which the design of the tunnel could move radially over a range of $100 \mathrm{ft}$. without violating the radiation criteria.

\subsection{Environmental Impact Statement (EIS)}

In response to the DOE ISP, 36 proposals which met all of the qualification criteria were received. A Best Qualified List (BQI) of eight sites was selected from this initial list of 36 by a task force convened by the National Academy of Sciences and the National Academy of Engineering. ${ }^{18}$ The Secretary of Energy 
committed the Department to include a completed an environmental impact statement as a condition for final selection of the SSC site. This entailed a full environmental impact study for each of the 8 sites on the BQI. ${ }^{19}$

Because the SSC would be a radiation generating machine, radiation impacts, particularly with respect to waste generation and ground water contamination were of significant concern. An Environmental Radiation Task Force under Prof. J. D. Jackson was formed at the $\mathrm{CD}$ ( $\mathrm{i}$ to analyze and document the potential radiation impacts and address mitigation measures. The Task Force Report ${ }^{20}$ is the hasis for the radiation considerations and findings in the Environmental Impact studies for all of the BQI sites, and in particular the chosen Texas site.

The lead agency in preparation of the environmental impact statement was the Department of Fnergy. The 1)()E Chicago (Operations (Office, the field office responsible for the project, engaged the Argonne National Laboratory (ANI) as its agent in preparing the EIS. ANI relied on the criteria of the ISP and the Jackson report for its evaluation of the radiation impacts on the sites.

Project-specific questions asked during the public hearing phase of the EIS process were referred back to the (I)(i. Responses to questions concerning radiation were generally prepared by 1)r. T. Toohig, with substantial assistance from the Health and Safety Department of Fermilab, notably Dr. L. Coulson and Dr. S. Baker.

One notable concern in the public hearings was the generation and transportation of low-level radioactive waste. With the help of the rermilab stalf, this was projected 10 be only a lew tens of cubic feet by extrapolation from the experience at rermilab.

In November 1988 the Texas site near 1)allas was selected for the site of the SSC, and a Record of Decision was issued by the Secretary of Energy on 8 January 1989.21 Following this selection a supplemental environment impact statement (SEIS) was prepared to tailor the specific environment impacts to the selected site. ${ }^{22}$ The Record of Decision for the SEIS was issued on 4 February 1991.

\subsection{DEFINING THE FOOTPRINT}

The adaptation of the SSC to the Texas site involved mapping the accelerator lattice onto the geography and geology of the site, minimizing the interference with existing surface features, and then configuring the land requirements to accommodate and contain the potential radiation contours. The configuration of the West and East Complexes to contain the radiation from the potential sources is shown in Figures 1 and $2 .{ }^{23}$ To minimize land acquisition, only an underground stratified fee volume was acquired, sufficient to contain the hadronic and muonic radiation to less than the stipulated guidelines. A cross-section of the stratified fee volume with its relationships (1) surface features is shown in Figure $3 .{ }^{23} \mathrm{~A}$ three-dimensional detailed digital mapping of the stratified fee volume based on the radiation requirements was provided to the State of Texas and is the basis for site acquisition. ${ }^{24}$ 


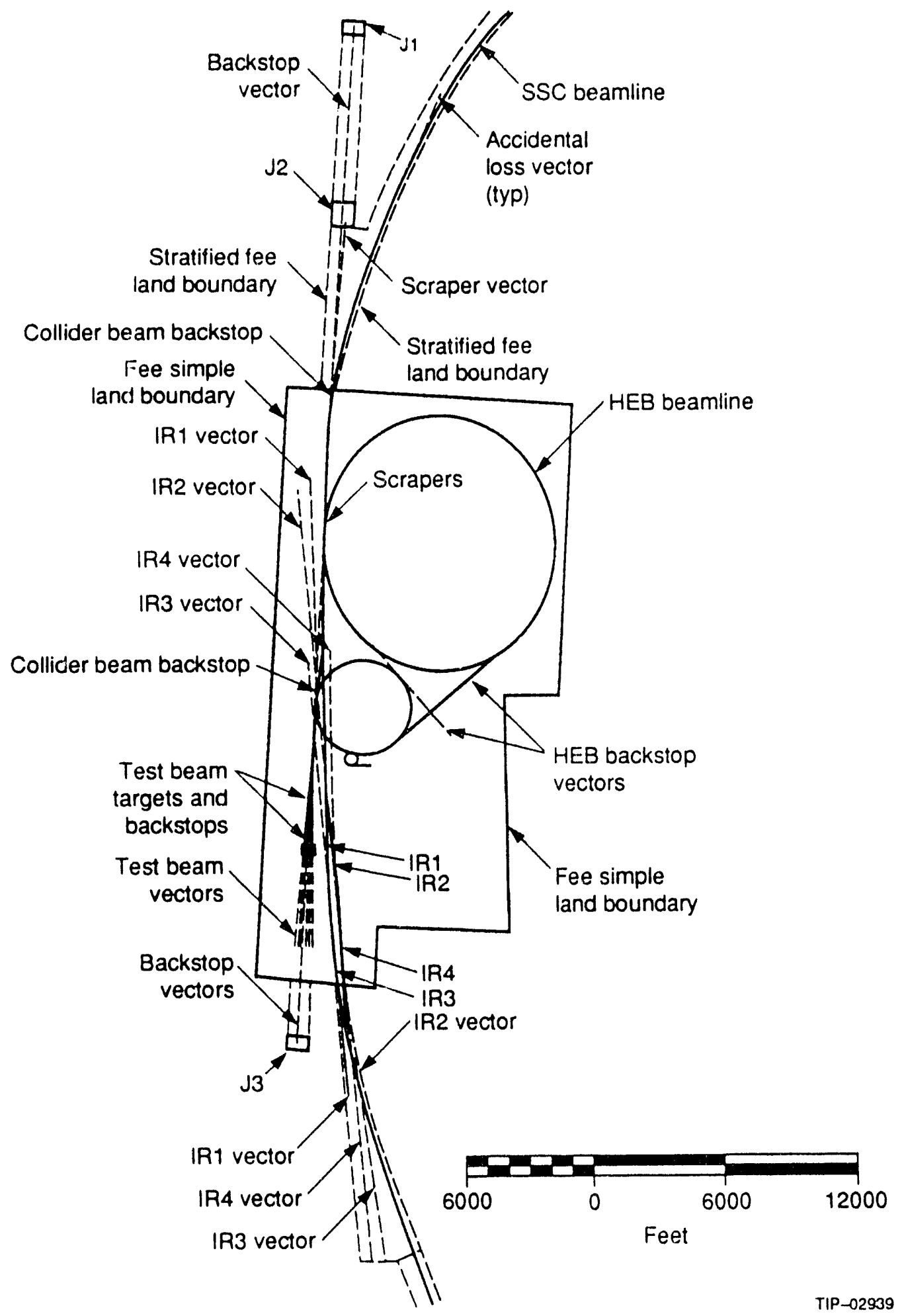

Figure 1. West complex radiation vectors. 


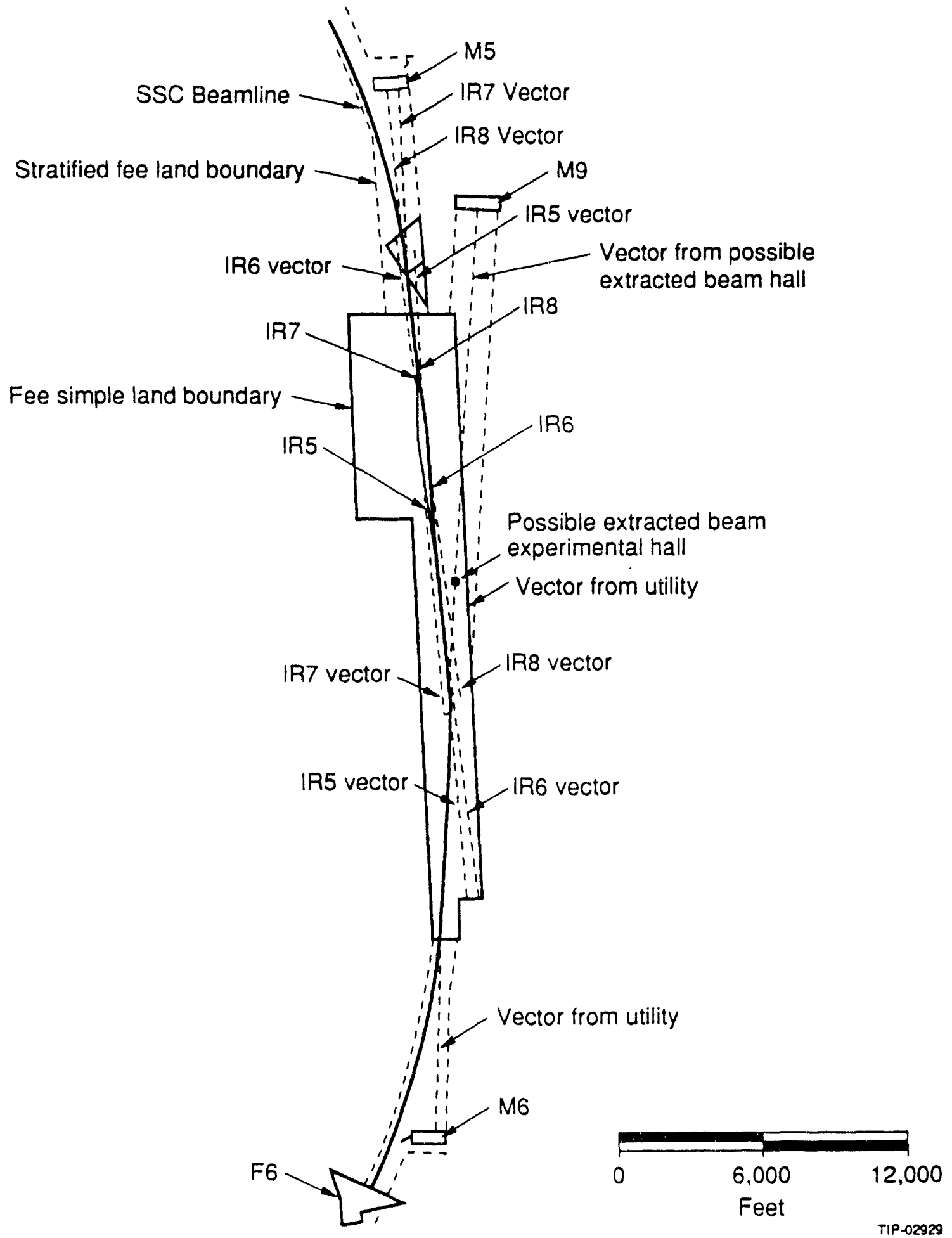

Figure 2. East complex radiation vectors. 


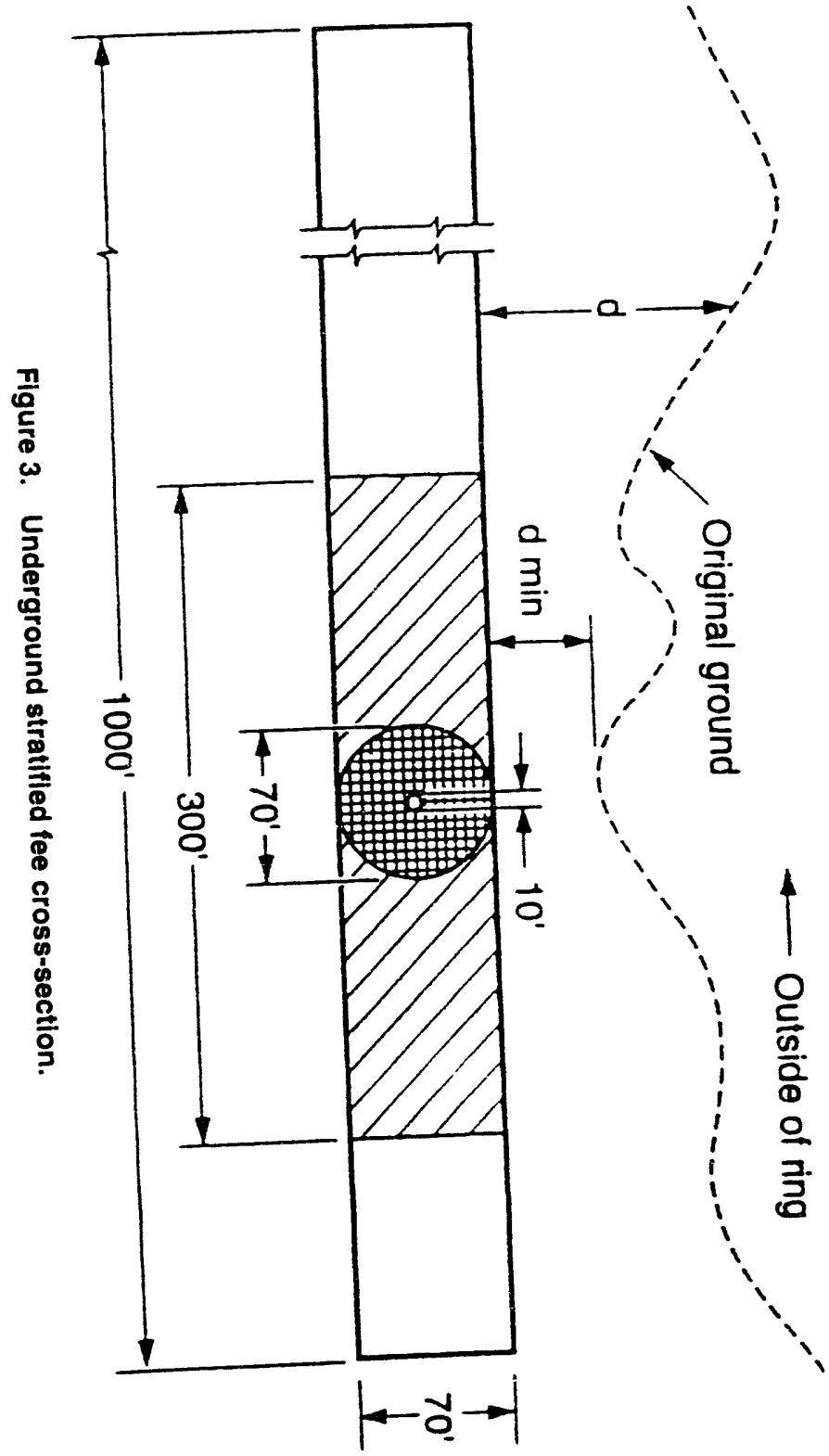




\section{REFERENCES}

1. Lederman, L, Proceedings of the 1982 DPF Summer Study on Flementary Particle Physics and Future Facilities, June 28-July 16, 1982, Snowmass, CO.

2. Report of the $20 \mathrm{TeV}$ Hadron Collider Technical Workshop Held at Cornell University March 28-April 2, 1983.

3. Preprint I.A-UR-83-3078, Site Allas for the Superconducting Super Collider, R. Slansky, Fall 1983.

4. Preprint L.A-UR-84-3893, Second Edition of the Site Allas for the Superconducting Super Collider, R. Slansky, Fall 1984.

5. D()E/HR-()213 Report of the Reference Designs Study Group on the Superconducting Super Collider, May $8,1984$.

idem, Appendix A, Design Details.

idem, Conventional Facilities.

idem, Technical Appendix (to Conventional Facilities).

6. Report of the DOE Review Committee on the Reference Designs Study, May 18, 1984.

7. SSC-106 Shielding Calculations for Multi-TeV Hadron Colliders, A. Van (iinneken et al., Jan 1987.

8. SSC Conventional Facilities: Phase 1-Work Prior to NTP, June 15, 1984.

9. SSC-15 Siting Parameters Document, June 15, 1985.

10. Fermilab Magnet Systems I)esign for SSC (draft), rev. March 20), 1984.

11. Excavation Cost Fstimates: Ring A Alignment for the Proposed Super Conducting Super Collider, Harza Engineering, February 1985.

12. SSC-SR-2020 Conceptual Design of the Superconducting Super Collider (with appendices), URA/SSC Central Design Group, March 1986.

13. DOE/ER-()267 Report of the DOE Review Committee on the Conceptual Design of the Superconducting Super Collider, May 1986.

14. SSC-SR-1016 SSC Workshop on Environmental Radiation 14-18 Octoher 1985, January 1986.

15. SSC-SR-1031 Workshop on Radiological Aspects of SSC Operations, May 1987.

16. SSC-SR-2()4() Siting Parameters Document, February 1987.

17. DOE/ER-0315 Invitation for Site Proposals for the SSC, April 1987, with Responses.

18. DOE/FR-()392 SSC Site Evaluations, SSC Site Task Force, November 1988.

19. DOE/EIS-0138 Final Environmental Impact Statement for the SSC, December 1988.

20. SSC-SR-1026 SSC Environmental Radiation Shielding, Task Force Report, J. D. Jackson, Ed., July 1987.

21. DOE/ER Implementation Plan for the Supplemental Fnvironmental Impact Statement for the SSC Project (with Record of Decision), July 199().

22. DOE/EIS-()138S Final Supplemental Impact Statement for the SSC, December 199().

23. SSCI-SR-1041 Footprint Characterization Document, September 1989.

24. SSC-SR-1049 Computer-Aided Design of the Digital Footprint, Rev. 1991.

Additional Documentation

SSC-147 A Guide to Understanding the Radiation Environment of the Superconducting Super Collider, L. Coulson, W. Freeman, T. Toohig, November 1987.

SSC-SR-1027 An Introduction to Radiation Protection for the Superconducting Super Collider, K. Metropolis, Ed., November 1987.

SSC Pamphlet, The Super Collider: Health, Safety, and the Environment, 1991. 

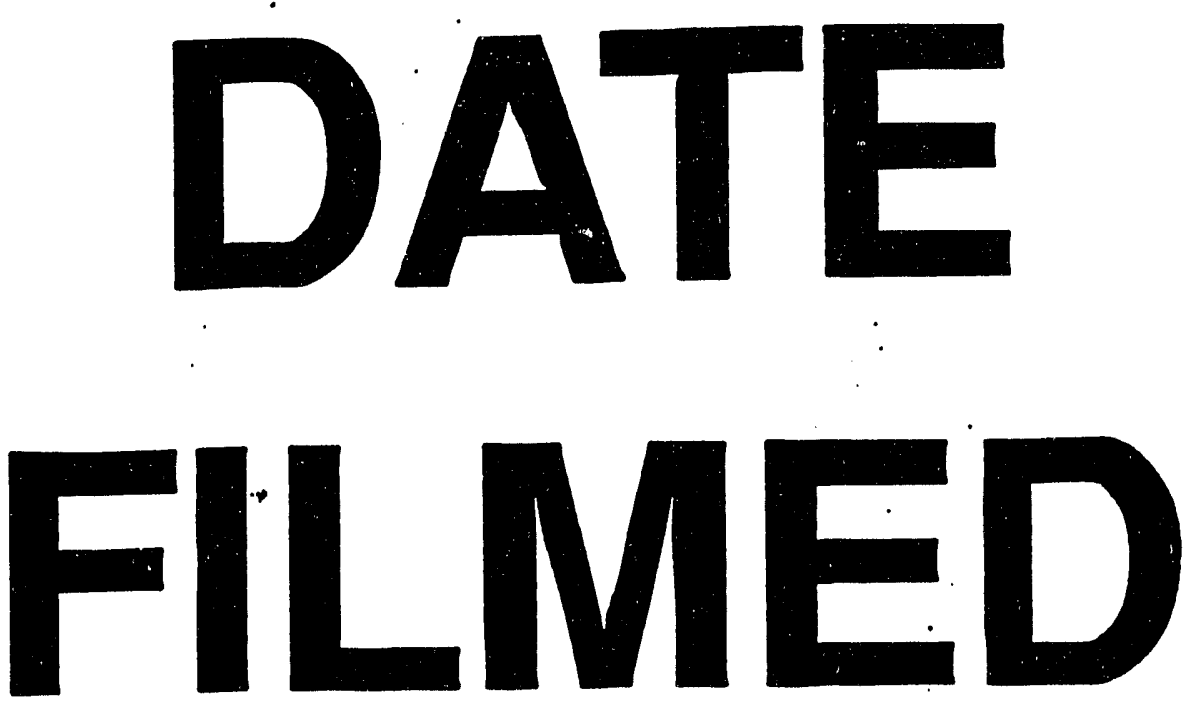

$1 / 27 / 94$
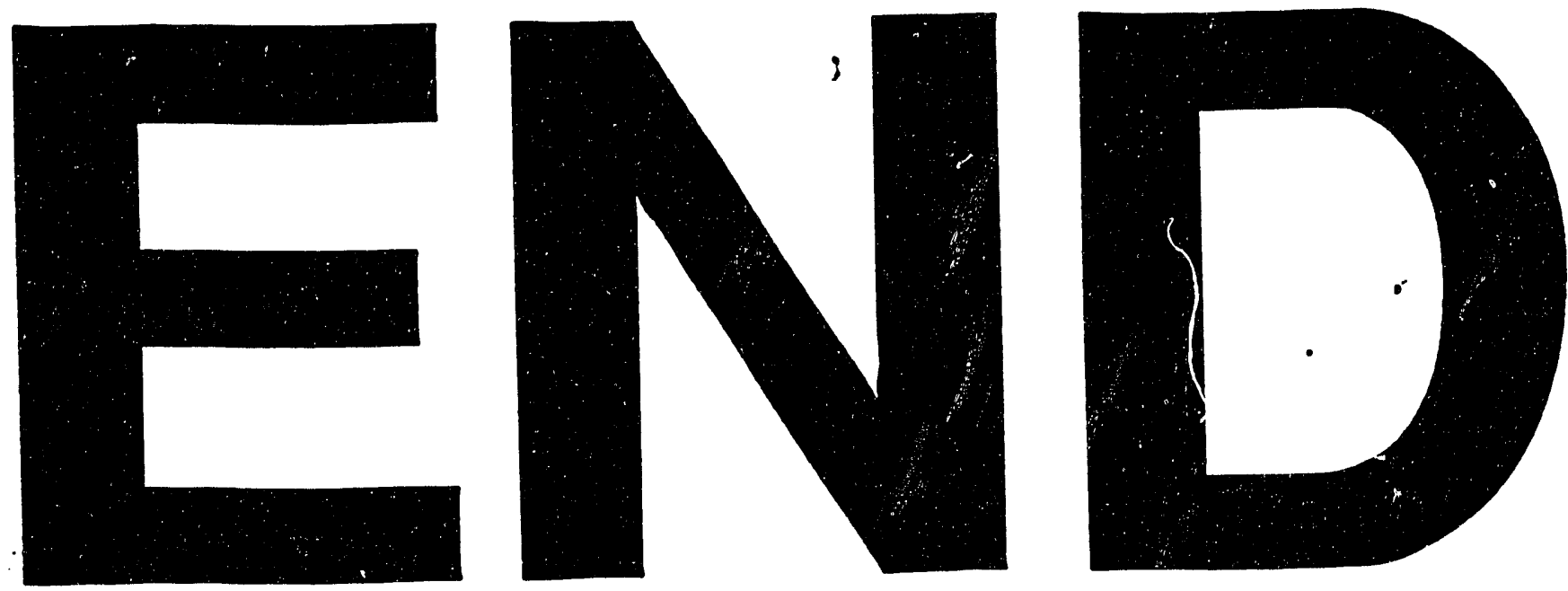
